\title{
Does Methergine Aggravate Chest Symptom and/or Electrocardiographic Changes during Cesarean Delivery under Spinal Anesthesia?
}

Department of Anesthesiology, Samsung Cheil Hospital, Sungkyunkwan University School of Medicine, Seoul, Korea

Jeong-Yeon Hong, M.D., and Jong In Oh, M.D.

Background: Complaints of chest symptoms including pressure, tightness, or pain frequently occur during cesarean delivery under regional anesthesia. The aim of this study was to test whether methergine (methylergonovine maleate) aggravates chest symptoms and/or ECG changes during cesarean section under spinal anesthesia, and to determine if these changes are associated with any discernable intraoperative event.

Methods: After delivery, patients were given intravenous methergine $0.2 \mathrm{mg}$ and diluted oxytocin 10 i.u. in $1000 \mathrm{ml}$ Ringer's lactate solution (Methergine group, $n=30$ ) or diluted oxytocin 20 i.u. (Control group, $n=29$ ). ECG and hemodynamic responses were monitored continuously on 12 leads perioperatively.

Results: Methergine significantly increased the incidence of chest symptoms compared to the control group (30\% vs. 3.4\%, $\mathrm{P}<0.05)$, but this increase was not correlated with ECG ST segment changes or with other intraoperative events. ECG changes suggestive of myocardial ischemia occurred in the two groups to similar extents (34.5\% vs. $30 \%, \mathrm{P}>0.05)$.

Conclusions: Methergine-induced chest symptoms per se do not signify evident myocardial ischemia during cesarean delivery. However, anesthesiologists must not overlook the possibility of a small coronary arteriolar spasm, especially in high-risk patients. (Korean J Anesthesiol 2005; 48: S 15 20)

Key Words: cesarean section, electrocardiogram, methylergonovine maleate, myocardial ischemia, spinal anesthesia.

\section{INTRODUCTION}

Complaints of chest symptoms like pressure, tightness, or pain frequently occur during cesarean section under regional anesthesia, but the details of this clinical condition have not been clarified sufficiently.

Palmer and colleagues believed that the association of electrocardiographic (ECG) changes and chest pain make it reasonable to speculate that myocardial ischemia may be their cause. ${ }^{1)}$ Although subsequent studies have failed to demonstrate impaired myocardial performance or ischemic injury as evidenced by creatine phosphokinase enzyme analysis, Holter

Received : April 28, 2004

Corresponding to : Jeong-Yeon Hong, Department of Anesthesiology, Samsung Cheil Hospital, Sungkyunkwan University School of Medicine, 1-19 Mukjeong-dong, Jung-gu, Seoul 100-380, Korea. Tel: 82-22000-7826, 1322, Fax: 82-2-2000-7785, E-mail: jenyhong@samsung. co.kr

No grants, no sponsors, no funding sources were provided For the financial support of this clinical research. monitoring, and two dimensional echocardiography, ${ }^{2,3)}$ the similarities of these complaints to the classical symptoms of myocardial ischemia have prompted us to undertake further evaluation for differential diagnosis of ischemia during or after the surgery. Further, serious symptom has important implications for the anesthetic management of patients.

Methergine (methylergonovine maleate) is a semisynthetic ergot alkaloid used for both prevention and control of uterine hemorrhage during the postpartum period. The drug directly contracts smooth muscle, which results in rapid and prolonged contraction of the uterus. However, myocardial infarction due to methergine has been reported in otherwise healthy postpartum women. ${ }^{4)}$ The purpose of this study was to determine whether the administration of methergine caused chest symptoms and/or ECG changes during cesarean section under spinal anesthesia with continuous 12 lead ECG monitoring, and if these changes were associated with maternal hemodynamic changes or intraoperative events. 


\section{MATERIALS AND METHODS}

After obtaining approval from our institutional review board and informed consent from the patients, sixty ASA physical status 1 or 2 women scheduled for elective cesarean section were studied. Patients with known cardiovascular disease, chronic hypertension, preeclampsia, or those taking antihypertensive or antiarrythmic medications were excluded from the study. A power analysis was performed to determine the sufficient sample sizes required establishing a significant difference in the percentage of patients for chest symptoms based on the results of preliminary study, using an value of 0.05 , and power of 0.9 . The calculated sample size was 47 in each group.

After intravenous infusion of $500 \mathrm{ml}$ lactated Ringer's solution, spinal anesthesia was performed with patients in the left lateral decubitus position at the L3-4 interspace using 1.8-2 $\mathrm{ml}$ of $0.5 \%$ hyperbaric bupivacaine. Patients were then turned supine and placed in left lateral tilt to achieve uterine displacement. Oxygen was delivered by loose fitting nonrebreathing facial mask at a rate of $5 \mathrm{~L} / \mathrm{min}$. Noninvasive arterial blood pressure (BP) and heart rate were measured each minute for the first $15 \mathrm{~min}$ and every $5 \mathrm{~min}$ thereafter. Sensory levels to pinprick were checked every $15 \mathrm{~min}$. Intravenous fluid and incremental $10 \mathrm{mg}$ dose of ephedrine were administered for the correction of hypotension, defined as $>20 \%$ decrease from baseline value in systolic BP. No supplemental opioid was administered.

The 12 lead ECG was monitored continuously via a MAC 1200 (Marquette Helige GnbH, Munzinger, Germany) beginning 15 min prior to initiation of the block and continued until the end of surgery. Vital signs were recorded five times or more while the patients were lying supine with a $15^{\circ}$ left lateral tilt: before anesthesia (baseline), after sensory block had been achieved, $2 \mathrm{~min}$ after delivery of the neonate, $5 \mathrm{~min}$ after intravenous administration of methergine $0.2 \mathrm{mg}$ and diluted oxytocin 10 i.u. in $1,000 \mathrm{ml}$ Ringer's solution (Methergine group, $\mathrm{n}=30$ ) or diluted oxytocin 20 i.u. (Control group, $\mathrm{n}=$ 29) after placenta extraction, skin closure, and at times of chest symptoms or ST segment changes. The monitor sounded an alarm when an ischemic event recognized and the anesthesiologist printed the ECG. Hemodynamic values, vasopressor use, any operative events, and patients' symptoms including pressure, tightness, or pain were recorded for each epoch. ST segments in all leads were analyzed by the ECG software, and confirmed by direct inspection of the investigator blinded to the anesthetic management; including adjustment for changes in $\mathrm{J}$ point and $\mathrm{T}$ wave morphology. ST segment depression of 1 $\mathrm{mm}$ or greater and ST elevation of $2 \mathrm{~mm}$ or greater for a minimum of $1 \mathrm{~min}$ were considered significant in this study. Results were expressed as mean \pm SD. Statistical analysis was performed utilizing a SPSS 10.0. The difference in the incidence of chest symptoms and ST segment changes between the two groups was tested using $x^{2}$ analysis, and the difference in the hemodynamic data was tested using independent $t$-test. The possible associations of chest symptom and ST segment change with the various recorded intraoperative variables were examined using the univariate $x^{2}$ analysis. The ability of intraoperative factors to predict any chest symptom and ECG change individually or in combination was tested using stepwise logistic regression. A $\mathrm{P}$ value $<0.05$ was considered significant.

\section{RESULTS}

Preoperative characteristics of the study population are presented in Table 1 and 2. Indications for elective cesarean section were previous cesarean section, breech presentation, or cephalopelvic disproportion. One patient from the control group

Table 1. Characteristics of Patients and Neonate

\begin{tabular}{lcc}
\hline & $\begin{array}{c}\text { Control group } \\
(\mathrm{n}=29)\end{array}$ & $\begin{array}{c}\text { Methergine } \\
\text { group } \\
(\mathrm{n}=30)\end{array}$ \\
\hline Maternal data & & \\
$\quad$ Age (yr) & $31.6 \pm 4.5$ & $31.9 \pm 3.2$ \\
Weight (kg) & $68.8 \pm 9.5$ & $65.0 \pm 7.2$ \\
Height (cm) & $160.0 \pm 4.1$ & $159.2 \pm 6.0$ \\
Gestational age (wk) & $38.5 \pm 0.8$ & $38.6 \pm 0.8$ \\
Parity (primi/multi) & $(9 / 20)$ & $(8 / 22)$ \\
Diagnosis (number of patients) & & \\
$\quad$ Previous surgery & 15 & 14 \\
$\quad$ Breech presentation & 8 & 10 \\
$\quad$ CPD & 6 & 6 \\
Neonatal data & & \\
Weight (kg) & $3.25 \pm 0.5$ & $3.17 \pm 0.4$ \\
1 min APGAR & $9(8-9)$ & $9(8-9)$ \\
5 min APGAR & $10(9-10)$ & $10(9-10)$ \\
\hline
\end{tabular}

Values are number of patients, mean \pm SD or median (range). CPD: cephalopelvic disproportion, primi: primigravida, multi: multigravida. There is no significant difference between the two groups. 
was excluded because cesarean hysterectomy was performed due to uterine atony after fetal delivery.

Significantly more patients in the methergine group complained of chest symptom during the surgery than in the control group (Table 3). However, ECG changes characteristic or suggestive of myocardial ischemia occurred similarly in the two groups. Six $(66.7 \%)$ of the nine symptomatic patients in the methergine group complained of chest pain 2-9 minutes after the administration of methergine, one patient (11.1\%) after spinal block, and another (22.2\%) after delivery. Only $21.5 \%$ of all ST segment changes occurred simultaneously with each symptom. ECG was recorded and cardiac enzymes were checked, and none of them showed positive results. Any therapeutic intervention was not undertaken for them. ECG changes and symptoms were transient in all cases; in all patients symptoms resolved and the ECG returned to baseline

Table 2. Intraoperative Data

\begin{tabular}{lcc}
\hline & $\begin{array}{c}\text { Control group } \\
(\mathrm{n}=29)\end{array}$ & $\begin{array}{c}\text { Methergine } \\
\text { group } \\
(\mathrm{n}=30)\end{array}$ \\
\hline Sensory block & $\mathrm{T} 3(\mathrm{~T} 2-\mathrm{T} 4)$ & $\mathrm{T} 3(\mathrm{~T} 2-\mathrm{T} 4)$ \\
Duration of surgery (min) & $56.3 \pm 7.1$ & $52.3 \pm 9.7$ \\
Total fluids infused (ml) & $2313 \pm 217$ & $2350 \pm 298$ \\
$\begin{array}{l}\text { Estimated blood loss (ml) } \\
\text { Urine output (ml) }\end{array}$ & $455.9 \pm 165$ & $511.4 \pm 243$ \\
Administration of ephedrine & $134.1 \pm 65.1$ & $111.8 \pm 40.5$ \\
(number of patients) & 11 & 13 \\
\hline
\end{tabular}

Values are mean \pm SD, median (range), or number of patients. There is no significant difference between the two groups.

Table 3. Symtoms and Electrocardiographic Changes

\begin{tabular}{lcc}
\hline & $\begin{array}{c}\text { Control group } \\
(\mathrm{n}=29)\end{array}$ & $\begin{array}{c}\text { Methergine } \\
\text { group } \\
(\mathrm{n}=30)\end{array}$ \\
\hline $\begin{array}{l}\text { Chest symptoms } \\
\text { Ischemic changes on ECG }\end{array}$ & $10(3.4 \%)$ & $9(30 \%)^{*}$ \\
$\begin{array}{l}\text { ST-elevation } \\
\text { ST-depression } \\
\text { ST-depression } \\
\text { with T-inversion }\end{array}$ & $3(10.3 \%)$ & $0(0 \%)$ \\
Nondiagnostic changes & $0(0 \%)$ & $3(10 \%)$ \\
\hline
\end{tabular}

Values are number of patients (\%). Nondiagnostic changes: ST segment depression of slightly less than $1 \mathrm{~mm}$ and $\mathrm{T}$ wave inversion without other changes. *: $\mathrm{P}<0.05$. by the conclusion of surgery.

Correlation between ECG change and patients' symptom was not statistically significant. Age, parity, systemic hypotension, vasopressor use, and intraoperative nausea did not show significant correlation with ST change or chest symptom at any time during the surgery. Stepwise addition of multiple symptoms did not improve the predictive value for these.

Patients with ECG changes were further analyzed to determine the time of first appearance of the change (Fig. 1). Onsets of changes were distributed similarly in both groups. Most of ischemic ECG changes in both groups appeared after spinal block or delivery of fetus (71.4\%) and after administration of oxytocin or methergine (21.4\%).

Maternal BP and heart rate along the time course are presented in Fig. 2 and 3. BP and heart rates during the surgery were not significantly different between the two groups. The number of hypotensive episodes was not significantly different between the two groups. No one showed hypertensive crisis after methergine in the methergine group. Compared to the baseline values, systolic BP of the patients in the control group were significantly decreased after spinal block and throughout the surgery. In the methergine group, systolic BP decreased significantly only after spinal block. In both groups diastolic BP were lower after spinal block than baseline and persisted until the end of surgery. Heart rates were significantly increased above baseline after delivery of fetus and after administration of methergine or oxytocin.

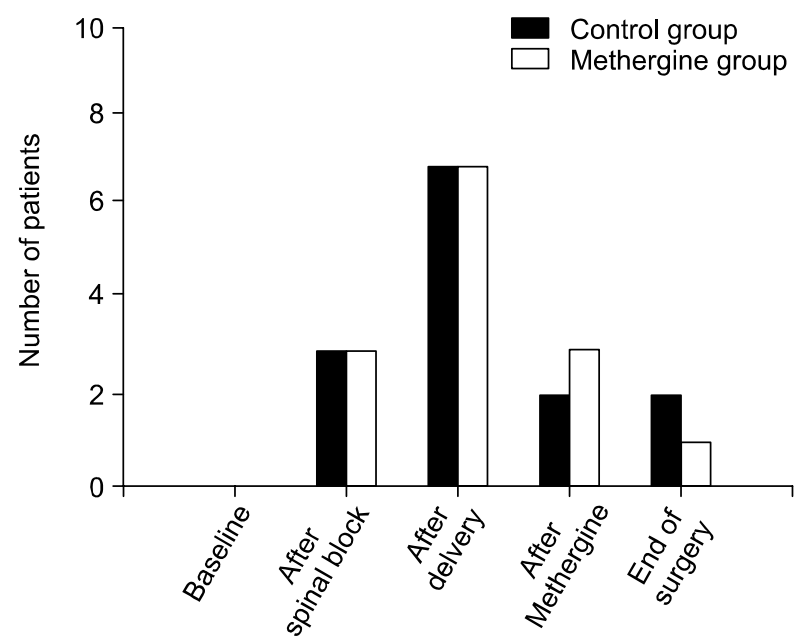

Fig. 1. Onset of changes were distributed similarly in both groups. Most ischemic ECG changes in both groups appeared rather after spinal block or delivery of fetus $(71.4 \%)$ than after administration of oxytocin or methergine $(21.4 \%)$. 


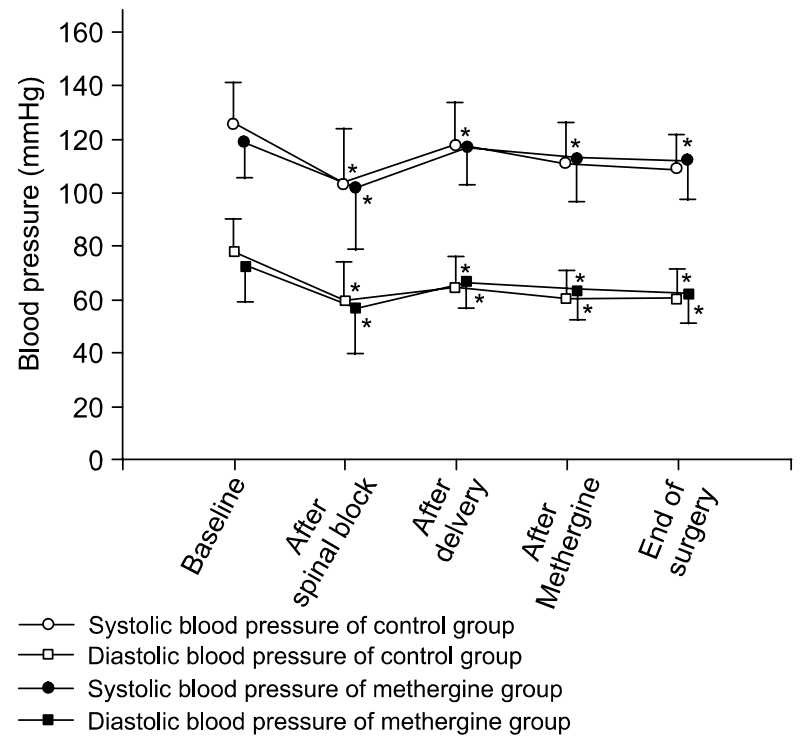

Fig. 2. Blood pressures during the surgery were not significantly different between the two groups. Compared to the baseline values, systolic blood pressures of the patients in the control group were significantly decreased after spinal block and throughout the end of surgery. In the methergine group, systolic blood pressures decreased significantly only after spinal block. In both groups, diastolic blood pressures were lower after spinal block than baseline and persisted until the end of surgery. *: $\mathrm{P}<0.05$ compared with baseline value.

Values were restored in both groups by the end of surgery.

\section{DISCUSSION}

Our data showed that up to $32 \%$ of patients developed ST segment changes during the intraoperative period, most often after delivery. This result confirmed that the ST segment changes on ECG have been reported to occur in 25-60\% of women undergoing cesarean section with regional anesthesia. ${ }^{1-3)}$ Myocardial ischemia, acute hypervolemia, hyperkinetic myocardial contractile state, hyperventilation, venous air embolism, heart rate-related normal changes, and diminished cardiac sympathetic tone have been proposed as mechanisms. ${ }^{1,6-8)}$ In this study, chest symptoms were not associated with ST segment changes. This is at variance with the findings of Palmer et al. ${ }^{1)}$ who reported that the majority of patients with such symptoms had ST segment changes and that none of the patients without ST segment changes had symptoms. Recently, many researchers have thought that the pattern of ST segment changes resemble inferior or anterolateral ischemia, yet ischemia should be unlikely in this healthy young patient population, and serial creatinine phosphokinase enzyme analysis and two dimensional

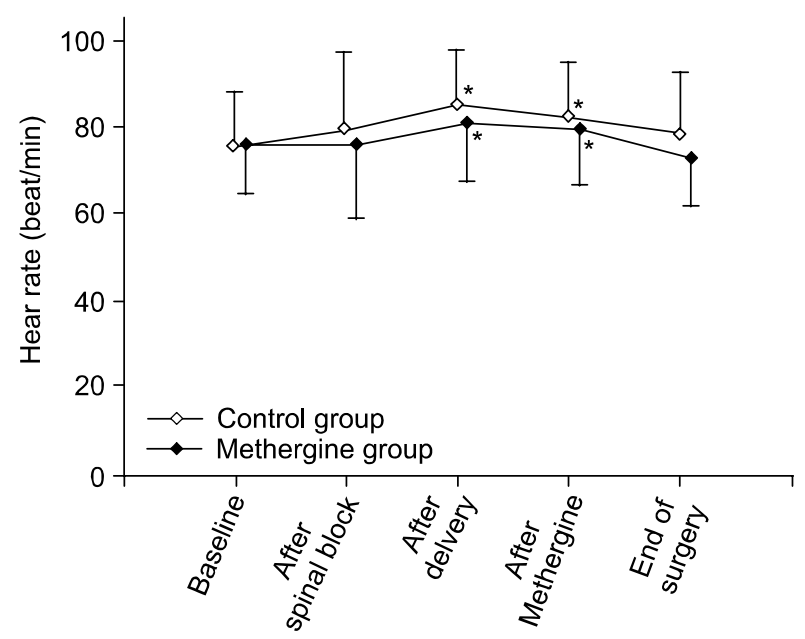

Fig. 3. Heart rates during the surgery were not significantly different between the two groups. Heart rates were significantly increased after delivery of fetus and after administration of methergine or oxytocin than the baseline values were restored in both groups. *: $\mathrm{P}<0.05$ compared with baseline value.

echocardiography fail to demonstrate evidence of myocardial ischemia or infarction. ${ }^{2,3)}$ Most of them concluded that ST segment changes during cesarean section are not caused by myocardial ischemia, and are not of any clinical consequence. Zakowski et al. ${ }^{3)}$ showed that the ST changes were preceded by tachycardia in many patients, which happened in this study also. The ECG findings were not different between the two groups and were not associated with symptoms. Chest symptoms per se do not signify myocardial ischemia during cesarean section. They may be caused by other factors such as bronchial spasm due to methergine or peritoneal traction. In this study, there was no oxygen desaturation or wheezing accompaning chest symptoms. Furthermore, the anesthetized sensory level was high enough that the uterus could be exteriorized in all patients during hysterotomy repair.

Why were chest symptoms actually aggravated by methergine in the results of the present study? Serota et al. ${ }^{9 \text { ) }}$ suggested that ergonovine-induced myocardial ischemia without epicardial coronary vasospasm may be the evidence for ischemia produced by small-vessel vasoconstriction. In the study of Shimada et al., ${ }^{10)}$ more than $50 \%$ of the patients felt anginalike chest pain after intravenous injection of methylergometrine maleate, but their ECG presented no ischemic changes. Meanwhile, stress thallium-201 $\left({ }^{201} \mathrm{TI}\right)$ myocardial scintigrams showed methylergometrine maleate-induced perfusion defects with complete redistribution in 12 of 21 patients. They succeeded in 
showing myocardial ischemia in patients in whom coronary arteriography or ECG detected no large coronary arterial vasospasm after methylergometrine maleate. These findings suggested that vasospasm in small coronary arteries caused myocardial ischemia in $60 \%$ of patients with chest pain.

In the case report of Kawakami and his fellows, ${ }^{11)}$ methergine was administrated to a 40 year-old female patient complaining of chest pain at rest. When methergine was administered intravenously and to the left coronary artery, she complained of chest pain within a few minutes after the injection; however, ECG remained unchanged. ${ }^{201}$ TI myocardial scintigraphy showed apical perfusion defect and complete redistribution in the delayed image. Apical perfusion defect can be attributed to myocardial ischemia of coronary arteries, which are too small to be detected by conventional diagnostic procedures. Vasospasm in small coronary arteries may be involved in this phenomenon although we really have no evidence. We did not include ${ }^{201}$ TI myocardial scintigraphy and microvascular spasm could not be diagnosed.

Usually, methergine can be administered intravenously or intramuscularly, but many clinicians suggest that, for safety concerns, the intramuscular route is preferable. ${ }^{12)}$ However, extreme hypertension has been noted with both routes of administration, and several cases of myocardial infarctions have been noted after administration of methergine both intramuscularly and orally. ${ }^{13,14)}$ Besides, in many clinical trials, methergine as single intravenous injection has been used for active pharmacologic management for reducing postpartum hemorrhage. ${ }^{15-17)}$ Fatal myocardial infarction tends to be limited to those patients who have an underlying risk factor for coronary artery spasm. In the 7 cases previously reported in the literatures, ${ }^{4,13,14,18,19)}$ methergine was taken by patients with predisposing factors for infarction such as migraine headaches, tobacco abuse, hypertension, coronary artery ectasia, or those who were concomitantly taking bromocryptine or other medications.

There were some flaws in the present study. The subjects were not randomized, and investigators were not blinded. This non-blinding may have introduced an element of bias, and thus data interpretation should be careful. Another limitation was the different doses of infused oxytocin between the two groups. Continuous infusion of oxytocin 20 i.u. per liter of crystalloid is a routine. ${ }^{20)}$ Methergine $0.2 \mathrm{mg}$ is also effective. To the methergine group, we administered oxytocin 10 i.u. to minimize the difference of contractions of uterine smooth muscle compared with the control group. Oxytocin has a direct relaxing effect on vascular smooth muscle and can cause a decrease in both systolic and diastolic BP. Oxytocin could have contributed to the observed ECG changes or chest symptoms by its systemic and coronary vascular effects. ${ }^{21)}$ However, in doses employed in this study, marked alterations in hemodynamics were not observed in the two groups. Although impossible to prove from the data collected in this study, oxytocin was unlikely to cause or contribute to chest symptoms.

In conclusion, methergine significantly increased the incidence of chest symptoms, but this increase was not correlated with ST segment changes of ECG or with other intraoperative events. ECG changes suggestive of myocardial ischemia occurred in the two groups similarly. Therefore, methergineinduced chest symptoms per se do not signify evident myocardial ischemia during cesarean delivery under spinal anesthesia. Anesthesiologist, however, must not overlook the possibility of small coronary arteriolar spasm especially in highrisk patients.

\section{REFERENCES}

1. Palmer CM, Norris MC, Giudici MC, Leighton BL, DeSimone CA: Incidence of electrocardiographic changes during cesarean delivery under regional anesthesia. Anesth Analg 1990; 70: 36-43.

2. McLintic AJ, Pringle SD, Lilley S, Houston AB, Thorburn J: Electrocardiographic changes during cesarean section under regional anesthesia. Anesth Analg 1992; 74: 51-6.

3. Zakowski MI, Ramanathan S, Baratta JB, Cziner D, Goldstein MJ, Kronzon I, et al: Electrocardiographic changes during cesarean section: A cause for concern. Anesth Analg 1993; 76: $162-7$.

4. Taylor G, Cohen B: Ergonovine-induced coronary artery spasm and myocardial infarction after normal delivery. Obstet Gynecol 1985; 66: 821-2.

5. Trotter TN, Langton JA, Barker P, Rowbotham DJ: Perioperative continuous monitoring of ST-segment changes in patients undergoing elective caesarean section. Br J Anaesth 1992; 69: 352-5.

6. Roy L, Ramanathan S: ST-segment depression and myocardial contractility during cesarean section under spinal anesthesia. Can J Anesth 1999; 46: 52-5.

7. Malinow AM, Naulty JS, Hunt CO, Datta S, Ostheimer GW: Precordial ultrasonic monitoring during cesarean delivery. Anesthesiology 1987; 66: 816-9.

8. Eisenach JC, Tuttle R, Stein A: Is ST segment depression of the electrocardiogram during cesarean section merely due to cardiac sympathetic block? Anesth Analg 1994; 78: 287-92.

9. Serota H, Kerm MJ, Deligonul U, Aguirre F, Caralis DG: Ergonovine-induced myocardial ischemia without epicardial cor- 
onary vasospasm: Evidence for ischemia produced by small-vessel vasoconstriction. Am Heart J 1991; 121: 1807-9.

10. Shimada T, Ishibashi Y, Murakami Y, Sano K, Tsukihashi H, Okada S, et al: Myocardial ischemia due to vasospasm of small coronary arteries detected by methylergometrine maleate stress myocardial scintigraphy. Clin Cardiol 1999; 22: 795-802.

11. Kawakami K, Shimada T, Nakayama K, Nagasaka Y, Tsukihashi $\mathrm{H}$, Murakami R, et al: Angina pectoris due to possible vasospasm of small coronary arteries. Clin Cardiol 1991; 14: 775-7.

12. Camann WR, Biehl DR: Shnider and Levinson's Anesthesia for Obstetrics. $4^{\text {th }}$ ed. Philadelphia, Lippincott Williams \& Wilkins. 2002, pp 361-71.

13. Iffy L, TenHove W, Frisoli G: Acute myocardial infarction in the puerperum in patients receiving bromocriptine. Am J Obstet Gynacol 1986; 155: 371-2.

14. Liao J, Cockrill B, Yurchak P: Acute myocardial infarction after ergonovine administration for uterine bleeding. Am J Cardiol 1991; 68: 823-4.

15. Sorbe B: Active pharmacologic management of the third stage of labor. A comparison of oxytocin and ergometrine. Obstet Gynecol 1978; 52: 694-7.

16. Andersen B, Andersen LL, Sorensen T: Methylergometrine during the early puerperium; a prospective randomized double blind study. Acta Obstet Gynecol Scand 1998; 77: 54-7.

17. Amant F, Spitz B, Timmerman D, Corremans A, Van Assche FA: Misoprostol compared with methylergometrine for the prevention of postpartum haemorrhage: a double-blind randomized trial. $\mathrm{Br}$ J Obstet Gynaecol 1999; 106: 1066-70.

18. Fujiwara Y, Yamanaka O, Nakamura T, Yokoi H, Yamaguchi H: Acute myocardial infarction induced by ergonovine administration for artificially induced abortion. Jpn Heart J 1993; 34: 803-8.

19. Nall KS, Feldman B: Postpartum myocardial infarction induced by methergine. Am J Emerg Med 1998; 16: 502-4.

20. Terui K: Textbook of Obstetric Anesthesia. $7^{\text {th }}$ ed. New York, Churchill Livingstone. 2000, pp 392-417.

21. Rall TW, Schleifer LS: The pharmacologic basis of therapeutics. $7^{\text {th }}$ ed. New York, MacMillan Publishing. 1985, pp 928-30. 